\title{
Mendelssohn und das Judentum
}

\author{
von Wilhelm Seidel (Leipzig)
}

Das Interesse an dem Thema ist groß. ${ }^{1}$ Die meisten Anfragen, die im Editionsinstitut der Mendelssohn-Briefe an der Leipziger Universität eingingen, galten ihm. ${ }^{2}$ Die Schreiber und Schreiberinnen setzten offenbar voraus, dass es Mendelssohns Korrespondenz erlaubt, den Einfluss des Judentums auf sein Leben und Werk zu studieren. Dies ist durchaus der Fall. Doch dürfte, was in den Briefen zutage tritt, erheblich von dem abweichen, was die Autoren der Anfragen erwartet haben mögen, und damit auch von dem, was ihnen die Literatur der letzten Jahrzehnte suggeriert hatte. Es schien mir deshalb an der Zeit zu sein, die Korrespondenz Mendelssohns im Blick auf das Thema durchzusehen und damit der Stimme Mendelssohns in der Diskussion über seine Identität Gehör zu verschaffen.

\section{Mendelssohn, der Jude}

Eric Werner hat 1963 ein Buch publiziert, das Mendelssohn aus einer neuen Sicht darstellt. ${ }^{3}$ Werner hatte vor dem letzten Weltkrieg in Deutschland und Österreich Musikwissenschaft studiert und musste, weil er Jude war, 1938 nach Amerika emigrieren. Sein Buch über Mendelssohn war eine, war seine Reaktion auf die Verbrechen, die die Deutschen an den Juden begangen hatten. Werner versuchte damit, Mendelssohn den Deutschen ein für alle Mal zu entziehen und in Sicherheit zu bringen. Er erklärte ihn zu einem jüdischen Komponisten und, was er geschaffen hatte, zu essentiell jüdischer Musik. Um diese Perspektive zur Geltung zu bringen, mobilisierte er seine ganze mathematisch disziplinierte Intelligenz und seine ganze enorme Leidenschaftlichkeit. Werner war von der Wahrheit seiner Sicht zutiefst überzeugt, so tief, dass er glaubte, ihr die Quellen anpassen und, wo es nottat, auch anzwingen zu dürfen. ${ }^{4}$ Und so konnte er ein Buch

\footnotetext{
${ }^{1}$ Grundlage der Studie ist die Riemann-Vorlesung, die ich im November 2009 auf Einladung des Instituts für Musikwissenschaft an der Universität Leipzig gehalten habe.

2 Mendelssohns Briefe werden, soweit bereits erschienen, zitiert nach der Ausgabe Felix Mendelssohn Bartholdy, Sämtliche Briefe, auf Basis der von Rudolf Elvers angelegten Sammlung hrsg. von Helmut Loos und Wilhelm Seidel, Kassel u. a. 2008 ff. Für den Namen Felix Mendelssohn Bartholdy steht im Folgenden die Abkürzung FMB.

3 Eric Werner, Mendelssohn. A new Image of the Composer and his Age, New York 1963. Die deutsche Ausgabe erschien unter dem Titel: Mendelssohn. Leben und Werk in neuer Sicht, Zürich und Freiburg i. Br. 1980. Dazu: Michael Saffle, Art. „Eric Werner", in: MGG2, Personenteil 17, Kassel u. a. 2007, Sp. 788-790.

${ }^{4}$ Um das Verfahren Eric Werners und seinen Einfluss auf die Forschung zu exemplifizieren, führe ich seine Darstellung des Augenblicks an, in dem 1819 der zehnjährige Felix Mendelssohn in Berlin mit dem Judenpogrom in Berührung kam, der mit dem Hetz-Ruf hep hep ganz Deutschland durchstürmte. Werners Schilderung lautet: Der Aufstand „war ein netter kleiner Pogrom, der sich in Berlin meistens nur in Plünderungen, Beschimpfungen und ähnlichen "Aktionen Luft machte. Ein königlicher Prinz ließ die schöne Gelegenheit nicht ungenutzt vorbeigehen: er spuckte vor dem zehnjährigen Felix aus, rief dazu: ,Hep, hep, Judenjung!' und ging seines Weges." Die Fußnote dazu vermerkt: „Veröffentlicht nur in Varnhagen von Enses ,Denkwürdigkeiten"“. Darin nun aber erscheint die Begebenheit in gänzlich anderem Licht: „Mit den Gewalttaten“ - liest man da - „mischte sich leichtsinnige Neckerei, Lust an Schalkheit; ein Königlicher Prinz rief dem Knaben Felix Mendelssohn auf der Straße lachend Hep, Hep! entgegen, es war nicht alles böse gemeint, manche der Schreier hätten nötigenfalls, wäre es weiter gegangen, den Juden sogar Beistand geleistet. Aber" - fuhr Varnhagen fort - „der rohe Übermut bedachte nicht, dass im Frevel kein Maß ist, dass aus Hohn und Schimpf auch Raub und Mord entstehen." Karl August Varnhagen von Ense, Denkwürdigkeiten seines Lebens, hrsg. von Konrad Feilchenfeld, Frankfurt a. M. 1987, Bd. 3, S. 542. Aus dem, was Varnhagen für eine neckische Randerscheinung des Pogroms ansah, wird aus Werners Sicht ein böser, zutiefst widerwärtiger, folgenschwerer Skan-
} 
vorlegen, das - wie er dachte - Mendelssohn die ihm ursprüngliche Identität, die eines Juden, wiedergibt und seine Musik auf ihre wahre Quelle, auf die Musik der Synagoge, zurückführt.

Seit Längerem sind Details des Buches von Werner Gegenstand kritischer Fragen und Bemerkungen. Und seit 2003 verfügen wir in Larry R. Todds Mendelssohn-Biographie ${ }^{5}$ über ein umfassendes Werk, das vorsichtig, aber doch unverkennbar auf Distanz zu der Werners geht und Mendelssohn damit aus der Position herausnimmt, in die ihn dieser gerückt hat. ${ }^{6}$ Todd liest die Quellen anders als Werner. Er geht offen auf die historischen Bedingtheiten des Lebens ein, das Mendelssohn geführt hat. Damit gewinnt die Frage nach der Identität Mendelssohns erneut Aktualität: die Frage also, ob er Jude war oder Christ, Jude oder Deutscher, Traditionalist oder Progressist und schließlich auch die Frage, ob sein OEuvre auf der Musik der Synagoge oder auf einer anderen musikalischen Tradition basiert.

Angesichts dieser Lage erschien es mir notwendig, grundsätzlich zu erkunden, was Mendelssohn über Juden und Jüdisches geschrieben und gedacht hat. Ich habe im Blick darauf die Briefe, die er geschrieben und auch die, die er empfangen hat, durchforscht, um die 10.000 Seiten, also fast alles, was bekannt ist; nur die Gegenbriefe der letzten zwei/ drei Jahre waren mir nicht vollständig zugänglich. Gemessen am Umfang dieses Corpus waren Zahl und Umfang der Fundstellen klein, so klein, dass ich zeitweise fürchtete, ich könne auf einer so schmalen Quellenbasis das Thema nicht schlüssig erörtern. ${ }^{7}$ Ich bin gleichwohl dabei geblieben, nicht zuletzt, weil die verhältnismäßig kleine Zahl der Belege einen Teil der Antwort auf die eingangs gestellte Frage ausmacht. Sie deutet darauf, dass das gestellte Thema nicht zu den Gegenständen zählt, die Mendelssohn kontinuierlich beschäftigt haben.

dal. Dieser - so Werner - habe Abraham Mendelssohn mit veranlasst, seine Kinder taufen zu lassen. Damit erklärte Werner ohne Rücksicht auf die Chronologie der Familiengeschichte die Begegnung des Prinzen mit Felix Mendelssohn zum entscheidenden Motiv für die Hingabe der Kinder an das Christentum. Dass er dafür die Taufe der Kinder um drei Jahre von 1816 auf 1819 verlegen musste, hat ihn offenbar nicht gekümmert. - Larry R. Todd korrigiert die Datierung der Taufe und teilt den Text Varnhagens korrekt mit, kann sich aber nicht dazu verstehen, ihn im Sinne des Autors zu akzeptieren, vgl. Larry R. Todd, Felix Mendelssohn Bartholdy. Sein Leben - seine Musik, Stuttgart 2008, S. 75 f. Er glaubt, Varnhagens Bericht für das skizzenhafte, feuilletonistisch aufbereitete Produkt eines „rangniederen Diplomaten" ansehen zu dürfen. Gewiss zu Unrecht: Jeder, der sich nur ein wenig mit Varnhagen bekannt gemacht hat, weiß, dass davon nicht die Rede sein kann. Varnhagen hat in Hamburg und Berlin in jüdischen Familien gearbeitet und mit ihnen in bestem Einvernehmen, ja in Liebe und Freundschaft gelebt. Er ist antisemitischen Äußerungen entgegengetreten, wo immer er darauf traf. Und er war der Gatte von Rahel Levin. Wenn einer den Judensturm ernst genommen hat, dann er. So hat er denn auch mit zwei Texten darauf reagiert, mit dem eigenen Bericht darüber und einem Brief dazu von Rahel. In seine Beschreibung ist die Bestürzung und Scham eingegangen, mit der er den Aufstand zur Kenntnis genommen hatte. Hässliche Flecken hinterlasse er - schrieb er - auf dem Ruhme Deutschlands. Der Brief Rahels ist ein Dokument der grenzenlosen Trauer, in die der Pogrom sie versetzt hat. Wenn Varnhagen also die Begegnung Mendelssohns mit dem Prinzen als Episode am Rande des Pogroms beschreibt, die der Prinz und der ihm offenbar bekannte kleine Musiker lachend hinter sich brachten, dann nicht weil er - wie Todd meint - einen Skandal verharmlosen wollte, sondern weil ihm die Begebenheit so bekannt gemacht worden ist. Im Übrigen: Varnhagen kam nach 1819 im preußischen Staatsdienst nicht mehr weiter, weil er ein liberal gesonnener Mann war, der die Institutionalisierung von Parlamenten mit Sympathie betrachtete und die Studentenverfolgung für ungerecht und unsinnig hielt.

${ }^{5}$ Larry R. Todd, Mendelssohn. A Life in Music, Oxford 2003.

${ }^{6}$ Dass Todd in Details, wie das in Anm. 4 angeführte Beispiel zeigt, mitunter Rücksicht auf Werners eigenwillige Deutungen nimmt, schwächt die Tendenz gelegentlich, setzt sie aber nicht außer Kraft.

${ }^{7}$ Dazu ist anzumerken, dass ich grundsätzlich nur Bemerkungen berücksichtige, die expressis verbis von Juden oder Jüdischem handeln. Ich gehe also beispielsweise nicht auf Mendelssohns freundschaftlichen Umgang mit Charlotte Moscheles ein, ziehe aber eine Reflexion in Betracht, die sein Vater gelegentlich über die Bedeutung ihres jüdischen Blutes zu Papier gebracht hat. 


\section{Der Übergang zum Christentum}

Mendelssohn hat - soviel ich sah - nie eigens und ausführlich dargelegt, wie er über Religion und über die Religionen denkt, vermutlich, weil die Fragen, die damit verbunden sind, durch die Eltern, im Wesentlichen wohl durch den Vater, entschieden worden waren. Dies war für die Eltern unumgänglich. Sie mussten sich damit befassen, weil sie entscheiden mussten, in welchem Glauben die Kinder zu erziehen seien: im jüdischem Glauben der Väter oder im christlichen Glauben ihrer Umwelt. Das Ergebnis ihrer Erwägungen ist bekannt: Abraham Mendelssohn, der Vater des Komponisten, ließ alle seine Kinder, schon Fanny, die ältere, 1805 geborene Tochter, und Felix, den älteren, 1809 geborenen Sohn, taufen, von Geburt an christlich erziehen und die Söhne nicht beschneiden. ${ }^{8}$ Es geschah dies im Verborgenen, weil Abraham Mendelssohn die jüdischen Großeltern schonen wollte. ${ }^{9}$ Er und seine Frau Lea gingen 1822 zum Christentum über.

Die Briefe, die im Blick auf diese Ereignisse geschrieben worden sind, gehören nicht zur Korrespondenz von Felix Mendelssohn. Ich gehe gleichwohl auf sie ein. Denn die Ein- und Vorstellungen, die darin zur Sprache kommen, muss man kennen, wenn man Felix Mendelssohns Bemerkungen über Juden und Judentum verstehen will. ${ }^{10}$ Was Abraham Mendelssohn bewogen hat, die Kinder christlich erziehen und taufen zu lassen, lässt ein Brief erkennen, den er Fanny, der älteren Tochter, zur Konfirmation geschrieben hat. ${ }^{11}$ Er teilte ihr darin mit, was er selbst für das innere Wesen von Religion ansah. Die Essenz von Religion, das Einzige, was daran unvergänglich ist - schrieb er Fanny -, sei der ewige „Hang zu allem Guten, Wahren und Rechten“ und das Gewissen, das diesen Hang überwacht. ${ }^{12}$ Das sei alles, was er über Religion wisse und über sie sagen könne. Was im Übrigen und gewöhnlich unter dem Titel Religion gelehrt würde und somit das Meiste, sei Menschenwerk, seien die variablen, historischen Formen, in denen der ewig geltende Kern verehrt werde. Abraham Mendelssohn verband seine ,Theologie' mit einer groben, der wohl landläufigen Geschichte der religiösen Formen. Für die erste, älteste hielt er die jüdische, für die mittlere die heidnische, die antike also, und für die jüngste die christliche, die - wie er meinte - nunmehr zeitgemäße. „Wir haben euch, Dich und Deine Geschwister" - schrieb er -, „im Christenthum erzogen, weil es die Glaubensform der meisten gesitteten Menschen ist und nichts enthält, was Euch vom Guten ableitet, vielmehr manches, was Euch zur Liebe, zum Gehorsam, zur Duldung und Resignation hinweist, sei es auch nur das Beispiel des Urhebers [Christi also], von so Wenigen erkannt und noch wenigeren befolgt. .13

Der Übergang vom Juden- zum Christentum bedeutete demnach für Abraham Mendelssohn nicht den Wechsel von einem zu einem anderen Gott, von einem zu einem

\footnotetext{
${ }^{8}$ Briefwechsel zwischen Goethe und Zelter in den Jahren 1799 bis 1832, hrsg. von Hans-Günter Ottenberg und Edith Zehm (= Johann Wolfgang Goethe, Sämtliche Werke 20.1), München 1991, S. 679.

9 Dass Heimlichkeit angezeigt war, macht die Härte deutlich, mit der Bella Salomon auf den Übergang ihres Sohns Jacob zum Katholizismus reagiert hatte. Siehe Sebastian Hensel, Die Familie Mendelssohn, Leipzig 181924, Bd. 1, S. $107 \mathrm{f}$.

10 Die dafür bedeutsamen Texte sind seit Langem bekannt und vielfach besprochen worden, dies indessen in einer Weise, die das, was sie aussagen, mehr oder weniger entwertet. Ich komme deshalb nicht umhin, sie hier in einer Weise zur Geltung zu bringen, die ihren Sinn und die darin zum Ausdruck gebrachte Gesinnung respektiert.

11 Abraham Mendelssohn Bartholdy hat den Brief 1820 in Paris geschrieben. Hensel, S. 112.

12 Ebd.

13 Ebd., S. 113.
} 
anderen Glauben, er bedeutete nicht mehr als den Übergang von einer Form der Religionsausübung zu einer anderen, war also ein Ereignis, das den Kern von Religion nicht berührt. Abraham Mendelssohn scheint Christus nicht als Stifter einer neuen Religion angesehen zu haben, sondern nur als „Urheber" einer neuen Form von Religiosität, einer Form allerdings, die den Kern insofern berührt, als sie den rauen Hang zum Guten im Sinne der christlichen Tugenden verfeinert und modernisiert, eine Verbesserung, von der sich Abraham Mendelsohn auch einen Fortschritt im Verkehr der Kinder mit den Eltern versprach. Nachdem der bereits augenleidende Abraham Mendelssohn von einer Leiter aus das Christusbild Wilhelm Hensels, seines Schwiegersohns, betrachtet hatte, schrieb er Felix nach Düsseldorf, das Gemälde werde nicht nur „außerordentlich schön“, sondern zudem neu. Hensels Christus sei „ein Christus, wie er es in sich war, das geläuterte, emporgehobene Judenthum, welches ihn, sehr charakteristisch, in seiner äußersten Verstecktheit umgiebt." ${ }^{14}$ Sein Christentum sah Abraham Mendelssohn als gereinigtes, gesteigertes, als fortgeschrittenes Judentum an.

Ein Brief Jacob Bartholdys, des Schwagers, lässt erkennen, dass die Taufe der Kinder Abraham Mendelssohn trotz des guten Grundes, den er dafür zu haben glaubte, beschwerte. Er fürchtete, damit das Gebot der Pietät gegenüber seinem Vater, gegenüber Moses Mendelssohn, verletzt zu haben. Der Schwager beruhigte ihn. Er sprach ihn frei mit einem starken Argument, dem überzeugendsten wohl, über das man damals verfügte. Er erklärte ihm, dass die Zeit auch über seinen Vater hinweggegangen sei, dass dieser an seiner Stelle nicht anders gehandelt hätte, als er es eben getan. Abraham Mendelssohn war wie sein Schwager ein Anhänger der Aufklärung und der mit ihr einhergehenden Fortschrittsideologie. Beide glaubten, dass der Übergang vom Juden- zum Christentum der Sittlichkeit zugute käme. Die Entscheidung für das Christentum sei - so Jacob Bartholdy - keine Entscheidung für eine grundsätzlich neue und andere, aber doch für eine „bessere Religion". Lebensklug zog er auch den Nutzen der Konversion für das Fortkommen der Kinder in Betracht: Wer sich nicht auf Gedeih' und Verderben an das alte Judentum gebunden fühle - erklärte er Abraham Mendelssohn -, begehe eine Barbarei, wenn er seine Kinder damit fürs Leben belaste. ${ }^{15}$

\section{Felix Mendelssohn Bartholdy über Juden und Jüdisches}

Die Zahl der Bemerkungen darüber ist - wie gesagt - im Verhältnis zum Umfang des Briefcorpus sehr klein. Es sind aber mehr, als ich im Folgenden vorweisen kann, doch

14 Abraham Mendelssohn Bartholdy an FMB am 30. September 1813, dazu Margaret Crumb, Correspondence of Felix Mendelssohn Bartholdy and Others (= Catalogue of the Mendelssohn Papers in the Bodleian Library, Oxford 1), Tutzing 1980, GB-Ob, SMS. M.D.M. d.28, Nr. 112.

${ }^{15}$ Hensel, S. 106 f. Mit dem Übergang vom Juden- zum Christentum stellte sich die Frage, ob es ratsam sei, die Konversion durch die Änderung des Namens anzuzeigen, den Namen Mendelssohn also abzulegen oder zu modifizieren. Die Frage hatte für die Mendelssohns eine eminente Bedeutung; denn sie trug den Namen des berühmtesten Juden der Epoche, den Namen Moses Mendelssohns. Jacob Bartholdy und Abraham Mendelssohn glaubten deshalb, dass die Familie ihre neue Identität durch einen neuen Namen zur Erscheinung bringen müsse. Jacob Bartholdy, der geborene Salomon, schlug den Namen vor, den er nach dem Übergang zum Christentum angenommen hatte. Abraham Mendelssohn zog es vor, den ererbten Namen um den Namen des Schwagers zu erweitern. Felix aber empfahl er gelegentlich, den Namen Mendelssohn abzulegen und sich nur Bartholdy zu nennen. Er schrieb ihm: „Einen christlichen Mendelssohn giebt es so wenig als einen jüdischen Confucius. Heißt Du Mendelssohn so bist Du eo ipso ein Jude, und das taugt nichts, schon weil es nicht wahr ist." Abraham Mendelssohn Bartholdy an FMB am 8. Juli 1829, dazu Crumb, GB-Ob, M.D.M. b.4, Nr. S. 71. 
glaube ich, alle wichtigen anzuführen und damit den Ambitus abzustecken, in dem sich die Korrespondenz bewegt.

\section{Über die Bedeutung des religiösen Bekenntnisses im täglichen Leben}

Mendelssohn und die Seinen pflegten die Menschen, mit denen sie verkehrten, nicht im Blick auf ihre Religion oder Konfession zu sondern, vermutlich weil sie diese nicht mit ihrem Wesen verbanden. Nur ausnahmsweise brachte man das religiöse Bekenntnis zur Sprache, dort nur, wo es einen besonderen Anlass dafür gab. Mendelssohn tat es in der Stadt Brandenburg, als er den Seinen 1828 mitteilen wollte, welchen der beiden Meyer, die zu besuchen er sich vorgenommen hatte, er schon gesehen hatte und welchen noch nicht: „Beim Dr. Meyer" - schrieb er - „war ich noch nicht (nämlich, wie der Gastwirth zum Adler sagt beim jüdischen; wohl aber beim christlichen Namensvetter) und zwar blos, weil mich bis jetzt St. ${ }^{16}$ noch nicht einen Schritt hat allein aus dem Hause thun lassen, sondern mich zu allen Bekannten selbst geleitete; morgen früh will ich hingehen." ${ }^{17}$ Mendelssohns Satz ist interessant: Denn er bestätigt eigens, obgleich indirekt, dass es im Hause Mendelssohn unüblich, vielleicht sogar unerwünscht war, Menschen im Blick auf ihren Glauben zu scheiden. Denn anders lässt sich kaum erklären, warum Mendelssohn die Unterscheidung ausdrücklich dem Ochsenwirt zugeschrieben und überdies im Brief einklammert hat.

\section{Über einen armen Juden und über reiche Juden}

Mendelssohn sprach das Judentum von Personen oder Gesellschaften nur dann an, wenn es in auffallender Weise zum Vorschein kam oder hervorgekehrt wurde. Gelegentlich beobachtete er 1830 im Park der Eltern einen alten, finsteren Mann. Er beschrieb ihn Rebecka, der jüngeren Schwester, Stück um Stück: Die Mütze, der Rock, das Haar, die Nase und die Physiognomie, alle - schrieb er - seien sie grau. Da der Alte so gar nicht in den bunten Garten passte, habe er den Gärtner gefragt, wer der ",alte fatale Jude" sei. Das sei, habe ihm der Gärtner gesagt, sein Vater, und sodann habe er ihm erklärt, was der alte Mann in dem Garten zu schaffen habe, nämlich für Humboldt ein Instrument einzurichten, also für Alexander von Humboldt einen Apparat im Observatorium zu installieren, das die Mendelssohns in ihrem Garten unterhielten. Wer nun glaubt, das Wort vom "fatalen Juden" wäre Mendelssohn peinlich gewesen, womöglich so peinlich, dass er sich dafür entschuldigt hätte, der irrt sehr. Er ließ es stehen und verband die Erklärung des Gärtners mit einer Kette von Assoziationen, die Glied um Glied absurder wurde und schließlich in reiner Narretei endete. ${ }^{18}$ Der Bericht über den grauen, alten Juden geht also unmittelbar in eine Distanzierung über, wie sie deutlicher und weiter kaum denkbar ist. Sie verliert sich schließlich in kindischen Wortspielereien. Man weiß: Mendelssohn hat den Brief geschrieben, um Rebecka, die an den Masern erkrankt war,

\footnotetext{
16 Justizrat Samuel Steinbeck. Er war der Gründer des Brandenburger Singvereins.

17 FMB an die Familie am 22. Oktober 1828, in: Mendelssohn, Sämtliche Briefe, Bd. 1, Nr. 126.

18 FMB an Rebecka Mendelssohn am 29. März 1830, in: Mendelssohn, Sämtliche Briefe, Bd. 1, Nr. 287. Die tolle Digression springt vom astronomischen Instrument, das der alte Jude zu richten hatte, zu Mendelssohns Musikinstrument und dessen Gesang, davon zum künftigen Nutznießer des Fernrohrs, dem Observanten, und endlich zu einem Besucher, der gekommen wäre, um ihn, Mendelssohn, zu observieren: zu Gustav Magnus, dem Sänger, und zu dem Spiel, das dieser wiederum mit den Namen gemeinsamer Freunde getrieben hätte.
} 
aufzuheitern. Wie hoch sich der junge Mendelssohn über den „fatalen Juden“ erhoben dünkte, zeigt er dennoch. Später hat er sich in ähnlicher Weise über Messjuden lustig gemacht, denen er auf einer Reise begegnet war. ${ }^{19}$

Distanz hielt Mendelssohn auch zu reichen Juden. Mitte 1835 lebte er kurze Zeit in Frankfurt am Main. Er betreute damals den Chor des Caecilien-Vereins, weil dessen Leiter erkrankt war. Während dieser Zeit verkehrte er auch in den Häusern Herz und Rothschild. Wohl fühlte er sich weder hier noch dort. Die Familie Herz war ihm „zu wenig bürgerlich". Er vermisste Stil und Anstand. Sie erwidere - klagte er - seine Besuche nicht und lade ihn nicht ein: „da kommen wir selten zusammen" ${ }^{\prime 20}$. Interessant und mehrschichtig ist das Verhältnis, das er zu den Rothschilds einnahm. Er hatte einerseits keine Lust, ihre Feste zu besuchen. Vor allem wohl, weil er Besseres zu tun hatte: Er kannte bereits Cécile Jeanrenaud, das schöne Frankfurter Mädchen, das er 1837 heiraten wird. Andererseits achtete er die Rothschilds durchaus und sah mit einem sehr eigenartigen Gefühl auf das, was sie waren und hatten. Er hatte Plaisir, wirkliches Plaisir - wie er schrieb - zu sehen, dass sie mit ihrem Reichtum und Ruhm den Philistern, den trägen, scheel blickenden christlichen Biedermännern, Ehrfurcht abnötigten, eben denen - wie er hinzufügte -, die sie, weil sie Juden sind, am liebsten prügeln würden. ${ }^{21}$ Dass dies so sei - schrieb er - bereite ihm eine wahre Freude, weil die Rothschilds alles „doch ganz allein ihrem Fleiße und ihrem Glücke verdanken. ${ }^{.22}$ Mendelssohn hielt Distanz auch zu den Rothschilds, aber die Achtung versagte er ihnen nicht.

\section{Über die Demütigung und Herabsetzung von Juden}

Im Februar 1831, während der Karnevalstage, durchstreifte Mendelssohn Rom und eilte von Vergnügen zu Vergnügen. „Sonnabend“ - berichtete er den Seinen - „ging man aufs Capitol, um zu erleben, wie die Juden sich ausbitten, wieder ein Jahr in der heil. Stadt geduldet zu werden, und wie man es ihnen am Fuß des Hügels erst abschlägt, und dann oben nach wiederholter Bitte gewährt und ihnen den Ghetto anweis't.. Die Zeremonie ließ die Juden wissen und fühlen, dass ihr Aufenthalt in der heiligen Stadt befristet ist, dass sie Jahr für Jahr erneut um ihre Duldung einkommen und dafür bezahlen müssen. Mendelssohn beobachtete die demütigende Zeremonie offensichtlich ohne innerliche Regung. In seinem Bericht findet sich kein Wort des Mitleids oder der Abscheu. Das einzige, was er beklagte, war, dass „das Ding“ sehr langweilig gewesen sei: „Man wartete

\footnotetext{
19 Mendelssohn unternahm im November 1833 eine Reise in die Umgebung von Düsseldorf, um nach Noten älterer Kirchenmusik zu suchen. Er brachte schon in Elberfeld einen ordentlichen Packen zusammen. Von dort fuhr er in einem Kabriolett nach Bonn und geriet darin in eine Gruppe von „sechs Meßjuden mit ihren Paketen unterm Mantel". „Das war" - schrieb er den Seinen - „eine curiose Reisegesellschaft". Die Kuriosität der Gesellschaft bestand vor allem darin, dass er, der Nichtjude, da er seine Noten auch unterm Mantel trug, sich nicht von den Messjuden unterschied. Mendelssohn nahm die seltsame Situation humoristisch und setzte sich, indem er sie so nahm, von den Juden ab. FMB an Rebecka Dirichlet, Fanny Hensel und Abraham Mendelssohn Bartholdy am 26. und 28. Oktober 1833, in: Mendelssohn, Sämtliche Briefe, Bd. 3, Nr. 810.

20 FMB an Lea Mendelssohn Bartholdy und Rebecka Dirichlet am 14. und 15. Juni 1836 (umdatiert), in: Mendelssohn, Sämtliche Briefe, Bd. 4, Nr. 1367.

21 Ebd. - Ein anderer Reflex der alten Judenfeindlichkeit findet sich in einer Bemerkung Rebecka Dirichlets. Sie habe - so ihre Mutter - nach einem Besuch bei den plötzlich reich gewordenen Devrients gesagt, „sie müßten einen Juden todgeschlagen haben" und könnten deshalb den neuen Reichtum mit gutem Gewissen genießen. Die Mutter dagegen dachte und sagte: „das Geld komme v. der Erbschaft seiner Eltern her." Lea Mendelssohn Bartholdy an FMB am 22. September 1838, dazu Crumb, GB-Ob, M.D.M. d. 34, Nr. 72.

22 FMB an Lea Mendelssohn Bartholdy und Rebecka Dirichlet am 14. und 15. Juni 1836 (umdatiert), in: Mendelssohn, Sämtliche Briefe, Bd. 4, Nr. 1367.
} 
2 Stunden und verstand endlich die Rede der Juden ebensowenig wie die Antwort des Christen." 23

Im Juni desselben Jahres beschrieb er Carl Friedrich Zelter, dem einstigen Lehrer, die Liturgie der Karwoche in der Peterskirche. Dabei erschien ihm „merkwürdig“, in welcher Weise die römische Passion die Worte der Juden, die des Volks ebenso wie die einzelner Juden, wiedergibt. Er hatte, als er sich darüber wunderte, gewiss die Turbae und die Stimmen der jüdischen Soliloquenten aus Bachs Matthäuspassion im Ohr. Im Vergleich damit kamen ihm die Juden der römischen Passion seltsam arglos vor. Es gäbe - schrieb er - nur „zahme Juden“. Um Zelter ihre Harmlosigkeit vor Augen zu führen, teilte er ihm das "Crucifige" der römischen Sänger in Noten mit. ${ }^{24}$

Mendelssohn ging alsdann auf das litaneiartige Gebet ein, das dem Vortrag der Leidensgeschichte folgt. Es enthält - schrieb er Zelter - „Gebete für alle Völker, und Institutionen, jedes einzeln genannt; bei dem Gebet für die Juden wird aber nicht gekniet, wie bei den andern, und auch nicht Amen gesagt; sie beten pro perfidis Judaeis, und das Büchlein weiß auch hiefür eine Erklärung zu finden." ${ }^{25}$ Über das exzeptionelle Gebet für die Juden hat sich Mendelssohn also gewundert. Auf die damit verbundene Verunglimpfung der Juden, die heute Empörung nicht nur unter den Juden hervorruft, aber glaubte er nur sagen zu sollen, dass sie ein Schriftchen der Kirche zu begründen weiß. Was diese Erklärung besagte, ist gewiss: Sie hat darauf verwiesen, dass die Juden Christus, Gottes Sohn, verraten und getötet und damit ein ungeheures Verbrechen begangen haben. Dazu Stellung zu nehmen, hielt Mendelssohn ersichtlich nicht für seine Sache, vielleicht auch weil er, der Christ, die Anschuldigung für zutreffend hielt. Im Übrigen stand ihm - wie man weiß - der Sinn nach gänzlich Anderem: Was ihn damals voll und ganz beschäftigte und was er Zelter schildern wollte, das war die Liturgie in der Peterskirche. In ihr kulminierte sein Romerlebnis. ${ }^{26}$

\section{Über judenfeindliche und judenkritische Redensarten}

Mendelssohn kannte wie jeder damals die landläufigen Redensarten über die vermeintlichen Untaten und üblen Eigenschaften der Juden. Er verfügte gelegentlich mit einer Unbedachtsamkeit darüber, die einen heute mehr als seltsam berührt. So bediente er sich gelegentlich der Rede, man habe Juden, die Brunnen vergiftet hätten, mit dem Tode bestraft. Offensichtlich griff er zu ihr, weil er glaubte, nur damit den Grad der Empörung zur Sprache bringen zu können, in den ihn eine Komposition von Louis Spohr, das Oratorium über Die letzten Dinge, versetzt hatte. Mendelssohn fand es matt und langweilig und glaubte zu erkennen, dass sich Spohr damit den Philistern anbiedern wollte, Leuten - wie er sagte -, die Mattes für heilig hielten. Die Spekulation darauf hielt er für ein Sakrileg: Es sei dies - schrieb er - „ein sündliches Spiel, mit Kleinlichkeiten“, eine Schändung also der heiligen Musik. Er steigerte die wahrhaft vernichtende Kritik in den Satz: „Man hängt die Juden, wenn sie einen Brunnen vergiften; aber die Musik ist ebensoviel werth, hoff ich, als ein Brunnen, und somit muß Spohr sterben. ${ }^{“ 27}$ Es ist klar: Mendels-

\footnotetext{
${ }^{23}$ FMB an die Familie am 8. Februar 1831, in: Mendelssohn, Sämtliche Briefe, Bd. 2, Nr. 396.

24 FMB an Carl Friedrich Zelter am 16. Juni 1831, in: Mendelssohn, Sämtliche Briefe, Bd. 2, Nr. 442, S. 292.

25 Ebd.

26 Dazu: Wilhelm Seidel, „Mendelssohns große Reise“. Vorwort zu: Mendelssohn, Sämtliche Briefe, Bd. 2, S. 19 ff.

${ }^{27}$ FMB an Lea Mendelssohn Bartholdy am 13. und 14. April 1829, in: Mendelssohn, Sämtliche Briefe, Bd. 1, Nr. 141.
} 
sohn, der damals Zwanzigjährige, machte sich mit dem Satz nicht das Argument der Judenfeinde zueigen und erst recht nicht die Todesdrohung, die es enthält. Er fordert nicht den Tod Spohrs, aber doch die Annullierung des Künstlers. ${ }^{28}$ Es ist das unter allen seinen Äußerungen, die auf Jüdisches anspielen, die problematischste. ${ }^{29}$

Nicht weniger erstaunlich ist eine Bemerkung seines Vaters über Charlotte Moscheles, die Frau des seinerzeit berühmten, mit dem Sohn befreundeten Pianisten Ignaz Moscheles. Nachdem Mendelssohn an Pfingsten 1833 in Düsseldorf das niederrheinische Musikfest dirigiert hatte, reiste er zusammen mit dem Vater nach London. Abraham Mendelssohn wurde dort das Opfer eines Unfalls und musste deshalb den Juli in London zubringen. Während dieser Zeit kümmerte sich nicht nur Charlotte Moscheles um ihn, sie indessen in besonders wohltuender Weise. Abraham Mendelssohn Bartholdy versäumte denn auch nicht, sie gegenüber Lea, seiner Frau, wortreich zu preisen. Die Eloge endet mit den Worten: Es sei eine „lebhafte, sehr bequeme, aufmerksame, nie peinliche, graziöse Gutmüthigkeit, mit der alles Gute geschieht, wie nur Frauen sie haben können, und unter diesen, vielleicht wieder mit besondrer Fertigkeit, eine gebohrene Deutsche und gewordene Engländerin“. Und dem fügt er hinzu: „Das jüdische Blut n'y gâte rien “30: Das jüdische Blut verdirbt dabei nichts. Die Nebenbemerkung lässt erkennen, wie wenig Mendelssohns Vater von der Natur der Juden hielt. Von Natur aus - meinte er wohl - hätten sie nichts, was sie auszeichnen könne, allein dadurch, dass sie Eingeborene und Zöglinge der fortgeschrittenen nationalen Kulturen würden, gewännen sie einen sittlichen Status, dem ihre Natur nichts mehr anhaben könne.

Und ähnlich dachte wohl der Sohn. Das Urteil, das er über den Wiener Verleger Pietro Mechetti abgegeben hat, basierte auf dem gleichen Vorurteil. Er hatte ihn 1830 auf der Reise nach Italien kennengelernt und ihm mehrere Werke, darunter die erste Symphonie, verkauft. ${ }^{31}$ Mechetti erfüllte den damals geschlossenen Vertrag nur zum Teil. Er zahlte das vereinbarte Honorar nicht, so dass Mendelssohn mahnen musste. ${ }^{32}$ Und er verkaufte die Symphonie 1833 dem Berliner Verleger Schlesinger. ${ }^{33}$ Mendelssohn verschaffte seinem Ärger darüber in einem Brief an die Eltern Luft. ${ }^{34}$ Er setzte sie ins Bild und ließ sie endlich wissen, was er über Mechetti denkt: Er - schrieb er - „ist aber doch ein gemeiner Kerl, kein Judensohn aber ein Jude, also das Gegentheil von mir." ${ }^{\text {“35 }}$ Mendelssohn bezeichnete also mit dem Wort Jude, wie die Judenverächter, einen unredlichen, unzuverlässigen Menschen. Juden, vor allem jüdischen Bankiers, sagte man nach, Verträge nach Gutdünken zu halten oder zu brechen. ${ }^{36}$ Es ändert an dem bösen

\footnotetext{
28 Später, 1835, ist FMB Spohr mit Achtung begegnet.

29 Das Verdikt spielt mit dem Gedankenmodell, das Richard Wagner in seinem Pamphlet über Das Judentum in der Musik auf die Spitze treiben wird, s. u.

${ }^{30}$ Abraham und FMB an Lea Mendelssohn Bartholdy am 1. und 2. August 1833, in: Mendelssohn, Sämtliche Briefe, Bd. 3, Nr. 766.

${ }^{31}$ Außer der Symphonie op. 11 die Klavierwerke: Rondo capriccioso op. 14, Fantasie über „The Last Rose of Summer“ op. 15 und Trois Fantaisies ou caprices op.16.

${ }^{32}$ FMB an E. Finis am 28. August 1831, in: Mendelssohn, Sämtliche Briefe, Bd. 2, Nr. 455.

33 Dazu: Felix Mendelssohn Bartholdy, Briefe an deutsche Verleger, hrsg. von Rudolf Elvers, Berlin 1968, S. 290 ff.

34 FMB an Abraham und Lea Mendelssohn Bartholdy am 28. und 29. Dezember 1833, in: Mendelssohn, Sämtliche Briefe, Bd. 3, Nr. 834.

35 Ebd.

${ }^{36} \mathrm{Zu}$ diesem Vorurteil siehe den Brief von Julius Fürst an FMB vom 22. Oktober 1839, dazu Crumb, GB-Ob, M.D.M. d. 36, Nr. 83. Demnach versieht jeder „gute jüdische Bankier“ einen Vertrag „mit dem Beisatz: Ich genehmige diesen Kontrakt, doch behalte ich mir vor, ihn nach Umständen auch nicht zu halten".
} 
Wort Mendelssohns nur wenig, wenn man weiß, dass er damit eine Wendung in ihr Gegenteil verkehrte, die einst Zelter, sein Lehrer, auf ihn gemünzt hatte. Zelter hatte Goethe 1821 mitgeteilt, er bringe seine Tochter Doris und seinen besten Schüler, den damals zwölfjährigen Felix Mendelssohn, mit zu ihm nach Weimar. Um Goethe auf den Besuch vorzubereiten, stellte er ihm den kleinen Felix wortreich vor: Er beschrieb die Größe seiner musikalischen Begabung, erwähnte die gute Erziehung, die er genossen, und schloss mit dem Zusatz, er sei „zwar ein Judensohn, aber kein Jude“. Die Bemerkung wurde publik, nachdem der dritte Band des Briefwechsels von Goethe und Zelter 1834 erschienen war. ${ }^{37}$ Mendelssohns Mutter reagierte sofort und empört darauf, nicht wegen ihrer Judenfeindlichkeit, sondern wegen der Plumpheit, mit der Zelter einst den zwölfjährigen Felix mit einem religiösen Bekenntnis in Verbindung brachte, dem er keinen Tag angehört hatte. Sie machte den Sohn unverzüglich auf Zelters Entgleisung aufmerksam. ${ }^{38}$ Der hielt sich nun aber nicht weiter damit auf, sondern kehrte Zelters Wort um und gab es - wie gesagt - an Mechetti weiter. Rebecka, die die Vorgeschichte des Worts vermutlich nicht kannte, nahm es zum Nennwert und protestierte gegen den Gebrauch, den der Bruder davon gemacht hatte: „Wie“ - schrieb sie ihm - „kannst Du Dich unterstehen zu schreiben Mechetti sey kein Juden[sohn], aber ein Jude. Was Teufel! Gebrauchst du Jude als Schimpfwort. Das ist nicht Deiner würdig." ${ }^{\prime 39}$

\section{Über Reste jüdischen Wesens}

Mendelssohn ist von Geburt an christlich erzogen worden. Es wäre deshalb erstaunlich, wenn sich in seinen Briefen Mitteilungen über erlebtes oder gar gelebtes Judentum fänden. Es gibt denn dafür auch keinen Beleg. Und daran ändert sich nur wenig, wenn man die Briefe der Korrespondenten mit in den Blick nimmt. Lea Mendelssohn Bartholdy, die Mutter, sie allein glaubte zu wissen, dass ihr etwas von ihrer Judenseele geblieben sei: dass sich diese rege, wann immer sie sich um Eine oder Einen der Ihren sorge. Nachdem Paul, der jüngere Sohn, 1834 zum Militärdienst eingerückt war, bedrückte sie der Gedanke, dass nun auch bald das Schießen losginge. „Meine kleine Judenseele ängstigt sich schon im voraus" - schrieb sie Felix nach Düsseldorf -, und lobte seine Weisheit, sich von „dieser Fatalität losgemacht zu haben" ${ }^{40}$ Lea war eine Frau, die gewöhnlich vernünftig dachte und handelte. Wenn es um das Wohl der Ihren ging, verließ sie indessen bisweilen ihre Rationalität und überkamen sie irrationale Ängste, dunkle Gefühle, die sie offenbar für Reste ihres abgelegten Judentums ansah.

\footnotetext{
37 Zelter an Goethe am 21.-31. Oktober 1821, in: Briefwechsel zwischen Goethe und Zelter, Bd. 1, S. 679.

38 Sie schrieb ihm: „Während Moses Mendelssohns in den französ. chambres und im engl. Parlament mit höchstem Lobe gedacht wird, weiß Z. nichts anders von Dir zu sagen als: er ist zwar ein Judensohn aber kein Jude! Pfui der kraßen, gemeinen Gesinnung! Z. hat sich in der Meinung der Menschen durch diese Publikation unglaublichen Schaden gethan: sowohl was den Charakter als den Geist betrift." Abraham und Lea Mendelssohn Bartholdy an FMB am 16. und 19. Dezember 1833, dazu Crumb, GB-Ob, M.D.M. d. 28, Nr. 172.

39 Rebecka Dirichlet an FMB am 15. und 16. Januar 1834, dazu Crumb, GB-Ob, M.D.M. d. 29, Nr. 9. - Vom Bild des geldgierigen Juden hat sich Mendelssohn gelegentlich abgesetzt. 1836 kam William Sterndale Bennett, ein sehr begabter englischer Pianist und Komponist, nach Leipzig, um bei Mendelssohn seine musikalischen Fähigkeiten zu perfektionieren. Bennett hatte vor, Mendelssohn dafür zu bezahlen. Mendelssohn weigerte sich, von ihm Geld anzunehmen. Er wäre andernfalls - schrieb er Klingemann - „ein Musikjudas“, das Ebenbild also des Erzjuden, der Christus um Geld verraten hat. Denn - so begründete er seine Entscheidung - er habe von der Anwesenheit Bennetts in Leipzig ebenso viel Nutzen wie dieser von ihm. FMB an Carl Klingemann am 20. Juni 1836, Felix Mendelssohns Briefwechsel mit Legationsrath Karl Klingemann, hrsg. von Karl Klingemann (jr.), Essen 1909, S. 202.

${ }^{40}$ Lea Mendelssohn Bartholdy an FMB am 22. Oktober 1834, dazu Crumb, GB-Ob, M.D.M. d. 29, Nr. $296 a$.
} 
Unter den vielen Korrespondenten des Sohns hat nur die Mutter ihrer frühen jüdischen Jahre gedacht. Als am 29. Dezember 1834 David Friedländer hochbetagt gestorben war, schrieb sie Felix: „Heut ist der letzte Pfeiler der ruhmbringenden Juden begraben; es knüpfen sich für mich der Erinnerungen an Kindheit, Jugend, Erziehung und ersten Ideen so mannichfache und bedeutende, daß Friedl.s Dahinscheiden wieder eine intereßante Epoche abschneidet und den Lebensriß erweitert. ${ }^{\prime 41}$ Friedländer, ein Freund und Gefährte Moses Mendelssohns, hatte demnach auf vielfältige Weise die frühen Jahre Leas geprägt. Mit seinem Tod - glaubte sie zu erkennen -, gehe die Zeit der großen, alten Juden unwiderruflich zu Ende, der Juden, die sich darum gemüht hatten, den Ihrigen die Errungenschaften der Aufklärung zu vermitteln. Lea Mendelssohn, die aufklärungsgläubige Frau, erklärte mit dem Tod des einstigen Lehrers die Epoche Moses Mendelssohns für abgeschlossen, ja mehr als dies: sie erklärte sie für abgeschnitten, für nunmehr endlich restlos vergangen. Dem Ausdruck der Pietät folgt denn auch nichts, was darauf deuten würde, dass sie die Verabschiedung des jüdischen Lebens bedauern würde oder gar für seine Wiederbelebung einträte. Sie begrüßte es vielmehr, dass mit dem Tod des letzten großen Juden auch die letzten Hindernisse gefallen sind, die dem Ausgriff in die Zukunft und damit dem Fortschritt noch im Wege standen: dass also wie sie sich ausgedrückt hat - der „Lebensriß" nun endlich frei erweitert werden kann.

Anfang Januar 1836 hörte Lea Mendelssohn von einem 22jährigen Breslauer Studenten namens Valentin. Dieser war in Paris für eine Entdeckung ausgezeichnet und danach von deutschen Universitäten "mit Anträgen ... bestürmt" worden. Der habe indessen - teilte sie dem Sohn mit - keinen davon angenommen, „weil er - ein zu frommer Jude sei“. Wie fern Lea Mendelssohn Bartholdy die Welt und das Verhalten des jungen Mannes war, zeigt ihr Kommentar: „Es giebt doch noch immer Originale!"42

Der - soviel ich sah - letzte Brief, der auf jüdisches Leben eingeht, stammt vom 6. Februar 1839. Darin geht es nicht mehr um jüdisches Wesen, sondern nur mehr um ein jüdisches Gebäck. Mendelssohn erkundigte sich bei Rebecka nach der Herstellung ihres Butterkuchens: „Cécile" - schrieb er ihr - „will durchaus wissen, ob solch ein Kuchen nur von Juden gebacken werden dürfe, und warum; kannst Du sie darüber aufklären? ${ }^{\text {"43 }}$ Rebeckas Antwort ist nicht bekannt.

\section{Über Judenemanzipation}

So desinteressiert die Mendelssohns an allem waren, was die jüdische Tradition anging, so offen und interessiert begrüßten sie, was die Emanzipation der Juden betraf und förderte. Als ein französischer Jude 1834 ein ansehnliches Amt erhalten hatte, beglückwünschte ihn Abraham Mendelssohn und bekundete Lea danach gegenüber Felix ihre Genugtuung darüber: „Sag mir nun Einer noch" - schrieb sie ihm -, „daß die Franzosen nicht in aller Aufklärung voran gehen! Nie und nirgend ist einem jud diese Ehre widerfahren! ${ }^{\prime 44}$

\footnotetext{
41 Abraham und Lea Mendelssohn Bartholdy sowie Rebecka Dirichlet an FMB am 29. Dezember 1834 (alte Abschrift in Privatbesitz).

42 Lea Mendelssohn Bartholdy an FMB am 5. Januar 1836, dazu Crumb, GB-Ob, M.D.M. d. 31, Nr. 6.

43 FMB an Rebecka Dirichlet am 6. Februar 1839, US-NYp, Mendelssohn Letters, Vol. IV C/6 (351).

${ }^{44}$ Lea Mendelssohn Bartholdy an FMB am 21. Juli 1834, dazu Crumb, GB-Ob, M.D.M. d. 29, Nr. 220.
} 
Im Sommer 1833 besuchten Felix und Abraham Mendelssohn in London Sitzungen, in denen Parlament und Oberhaus über die Emanzipation der Juden debattierten und entschieden. Felix berichtete am 12. Juli gut gelaunt, dass die Bill im Unterhaus mit großer Mehrheit angenommen worden sei. Dies - schrieb er den Seinen - „amüsirt mich prächtig ${ }^{\prime 45}$. Sein Vater musste Anfang August freilich mitteilen, dass die Bill im Oberhaus durchgefallen sei. Die Berliner - fügte er bissig hinzu - würden sich darüber freuen, allerdings weniger, wenn sie läsen, dass „der vorzüglichste Gegner [der Judenfeinde], der Erzbischof von Canterbury, der mit einem Lobe der Juden durch alle Prädicate, angefangen, [...] bei dieser Gelegenheit auch meines Vaters ehrenvoll erwähnt" hat. ${ }^{46}$

\section{Über Musik für die jüdische Gemeinde in Hamburg}

Die meisten Quellen, die ich bisher angeführt habe, stammen aus der Zeit vor 1835/36. Danach tritt das bis dahin schon nebensächliche Thema vollends zurück. Die wenigen Belege aus der Zeit danach aber haben dafür mehr Gewicht als die bislang vorgelegten. Es kommen darin spezifisch jüdische Interessen und Gegenstände zur Sprache.

Im November 1843 wandte sich Maimon Fraenkel, der Vorsteher der jüdischen Gemeinde in Hamburg, an Mendelssohn und bat ihn um die Komposition eines Psalms. Die Gemeinde - schrieb er - wolle die Feier ihres fünfundzwanzigjährigen Bestehens damit ausstatten. Offenbar glaubte Fraenkel, Mendelssohn den Charakter der jüdischen Liturgie vorstellen zu müssen. Er tat es jedenfalls wortreich. Ihre Texte - so Fraenkel - seien sehr reich an „empfindungsvollen Ausdrücken, an prägnanten Bildern, ja so zu sagen an dramatischen Situationen, die dem Tondichter ein willkommenes, noch kaum bearbeitetes Feld darbieten, so wie andererseits unsere Gemeinde [...] sehr empfänglich [ist] für die Musik und die durch sie zu erzielende Erhöhung des allgemeinen Schönheitssinnes ${ }^{\prime \prime 47}$. Mendelssohn versprach offenbar, die Bitte zu erfüllen. Denn Anfang Januar 1844 dankte ihm Fraenkel für seine Zusage und nannte ihm die Psalmen, die er für geeignet hielt. Er teilte weiter mit, über welche Kräfte die Gemeinde verfüge: bei einer außerordentlichen Gelegenheit wie der vorliegenden könne man mit „40 Damen und Herren (jüdischen und christlichen Glaubens)" 48 rechnen. Die Begleitung bittet Fraenkel auf die Orgel zu beschränken. Das Instrument, das das neue Gotteshaus erhalte, sei freilich „ziemlich groß“. Schließlich ersucht er Mendelssohn, den Psalm in Form einer Kantate zu komponieren und dabei auf die Übersetzung seines Großvaters zurückzugreifen.

Der Brief ist - nach dem, was ich bislang gesehen habe - einzigartig in der Korrespondenz. Es kommen darin Eigenheiten der jüdischen Liturgie zur Sprache. Er lässt erkennen, dass die Hamburger Gemeinde bemüht war, einen außerordentlichen Gottesdienst mit einer Musik auszustatten, die auf der Höhe der Zeit ist. Und er macht ersichtlich, dass bei der Aufführung der Kantate Juden und Christen zusammenwirken werden und

\footnotetext{
45 FMB und Carl Klingemann an Rebecka Dirichlet und die Familie am 23. Juli 1833, in: Mendelssohn, Sämtliche Briefe, Bd. 3, Nr. 759. Das Amüsement, das die Sitzung Mendelssohn bereitete, beruhte wohl nicht zuletzt auch auf der hohen Qualität der Reden, die damals gehalten worden sind.

46 Abraham und FMB an Lea Mendelssohn Bartholdy am 1. und 2. August 1833, in: Mendelssohn, Sämtliche Briefe, Bd. 3, Nr. 766. Nicht nur das Oberhaus, auch der König hatte das Gesetz abgelehnt. Dazu: Friedrich Battenberg, Das Europäische Zeitalter der Juden, Darmstadt 1990, Teilband 2, S. 138, und Todd, S. 320 f.

47 Maimon Fraenkel an FMB am 14. November 1843, dazu Crumb, GB-Ob, M.D.M. d. 44, Nr. 185.

48 Maimon Fraenkel an FMB am 8. Januar 1844, dazu Crumb, GB-Ob, M.D.M. d. 45, Nr. 15.
} 
eine ansehnliche Orgel zur Verfügung stehen wird. ${ }^{49}$ Die Kantate ist, wenn sie Mendelssohn denn komponiert hat, nicht erhalten.

\section{Über Moses Mendelssohn}

Die Familie begegnete Moses Mendelssohn mit Ehrfurcht, auch Felix Mendelssohn. Sie begrüßte es, wenn man seiner und seiner Verdienste um die Judenemanzipation gedachte. Aber innerlich scheint sie nicht mit ihm gelebt zu haben. Felix Mendelssohn hat die Distanz, auf die die Familie mit dem Übergang zum Christentum zu ihm gegangen war, lebenslang gewahrt. Dabei scheint auch Scheu vor seiner Größe eine Rolle gespielt zu haben. Das Bild, das er sich von seinem Großvater gemacht hatte, scheint mit dem Nathans, des Weisen, und dem des alten trauenden Juden auf Eduard Bendemanns damals berühmtem Gemälde (vgl. Abbildung) verschmolzen zu sein. ${ }^{50}$

In seiner Korrespondenz vor 1838 aber findet sich kein Wort über den Großvater, das Gewicht hätte, danach wohl das eine oder andere, das der Beachtung wert ist, aber auch hier keines, das darauf hinweisen würde, dass der Enkel sich auf die Gedankenwelt des alten Juden eingelassen hätte. Anfang 1838 bittet er die Mutter, ihm „doch die Psalmen, vom Großvater übersetzt,“ zu schicken; er kennt den Band und weiß, wo er zu finden ist: Die Psalmen „müssen sich" - schreibt er - „in der Bibliothek des Vaters, schwarz eingebunden mit roth, finden", er brauche sie "auf ein Weilchen zum Componiren"51. Eine andere Bemerkung aus dem gleichen Jahr lässt immerhin erkennen, dass er Briefe „mit wahrem Genuß und mit Dankbarkeit" gelesen hat, die Lessing an Nicolai, Gleim, Ebert $^{52}$ und auch an den Großvater gerichtet hatte. Er empfiehlt Rebecka es ihm nachzutun. Denn der „Prachtkerl“, Lessing, mache einen auch nach dem „dummsten Tag" wieder frisch. 53

Längere Zeit hatte Felix Mendelssohn mit Moses Mendelssohn erst zu schaffen, nachdem ihn 1840 einer der Brüder Brockhaus, vermutlich Heinrich, ${ }^{54}$ darauf aufmerksam gemacht hatte, dass die Schriften des Großvaters in keiner zuverlässigen Ausgabe vorlägen. Felix Mendessohn nahm sich des Problems an und bat Joseph Mendelssohn, den ältesten Sohn des Großvaters, um Hilfe. Die Ausgabe kam zustande. Am 27. Januar 1843

\footnotetext{
49 Ebenso deutlich wie Fraenkel bekundete General Karl Emil von Webern am 4. Mai 1846 (dazu Crumb, GB-Ob, M.D.M. d. 49, Nr. 247) sein Interesse an der Kunst Mendelssohns. Der Elias - schrieb er - sei für Juden der beste Gottesdienst. Denn das Oratorium lasse sie "das Walten und Wehen einer alles erhaltenden und führenden Liebe" fühlen und ahnen. Juden teilten demnach mit Christen die romantische Idee der Kunstreligion, die Vorstellung also, dass wahrhaft große Musik Medium göttlicher Offenbarung sein könne.

50 Welchen Rang man dem Bild zusprach, zeigen die Sätze, die FMB in einem Brief an Gustav Droysen dem Werk widmete, nachdem Bendemann sich um die Leitung der Dresdener Gemäldegalerie beworben hatte. Sie lauten: „Du hättest nur das allgemeine Interesse sehen sollen an den Unterhandlungen mit Bendemann und seiner Anstellung in Dresden, die immer noch ein Tagesgespräch ist; zu dem großartigen Kunsturtheile, das da meint, der Künstler sei so eine Art Schuldner und der Publicus ein Gläubiger, der den armen demüthigen Wicht um das Seinige mahnt, zu dem haben sie sich noch nicht erhoben, und meinen, der sei für Lebzeiten ein gemachter Mann, der den Jeremias und die trauernden Juden gemalt hat, auch ohne Anstellung auf Lebenszeit oder Pension. " FMB an Johann Gustav Droysen am 14. Dezember 1837, Ein tief gegründet Herz. Briefwechsel Felix Mendelssohn Bartholdy mit Johann Gustav Droysen, hrsg. von Carl Wehmer, Heidelberg 1959, S. 49. Lea Mendelssohn bemerkte zu dem Bild, Physiognomiker hätten in dem weiblichen Profil „die jüdische Beharrlichkeit und den Trotz erkennen wollen“. Darin - meinte sie - sei „etwas Wahres", Lea Mendelssohn Bartholdy an FMB am 10. Januar 1838, dazu Crumb, GB-Ob, M.D.M. d. 33, Nr. 157.

51 FMB an Lea Mendelssohn Bartholdy am 15. Januar 1838, US-NYp, Mendelssohn Letters, Vol. IV B/349 (C 51). FMB hatte die Übersetzung parat, als die Bitte von Maimon Fraenkel aus Hamburg bei ihm eintraf.

52 Johann Arnold Ebert, 1723-1795, war Dichter, Übersetzer und Lehrer für Englisch in Braunschweig.

53 FMB an Rebecka Dirichlet am 5. November 1838, US-NYp, Mendelssohn Letters, Vol. IV B/384 (B 61).

54 FMB nennt den Vornamen nicht.
} 


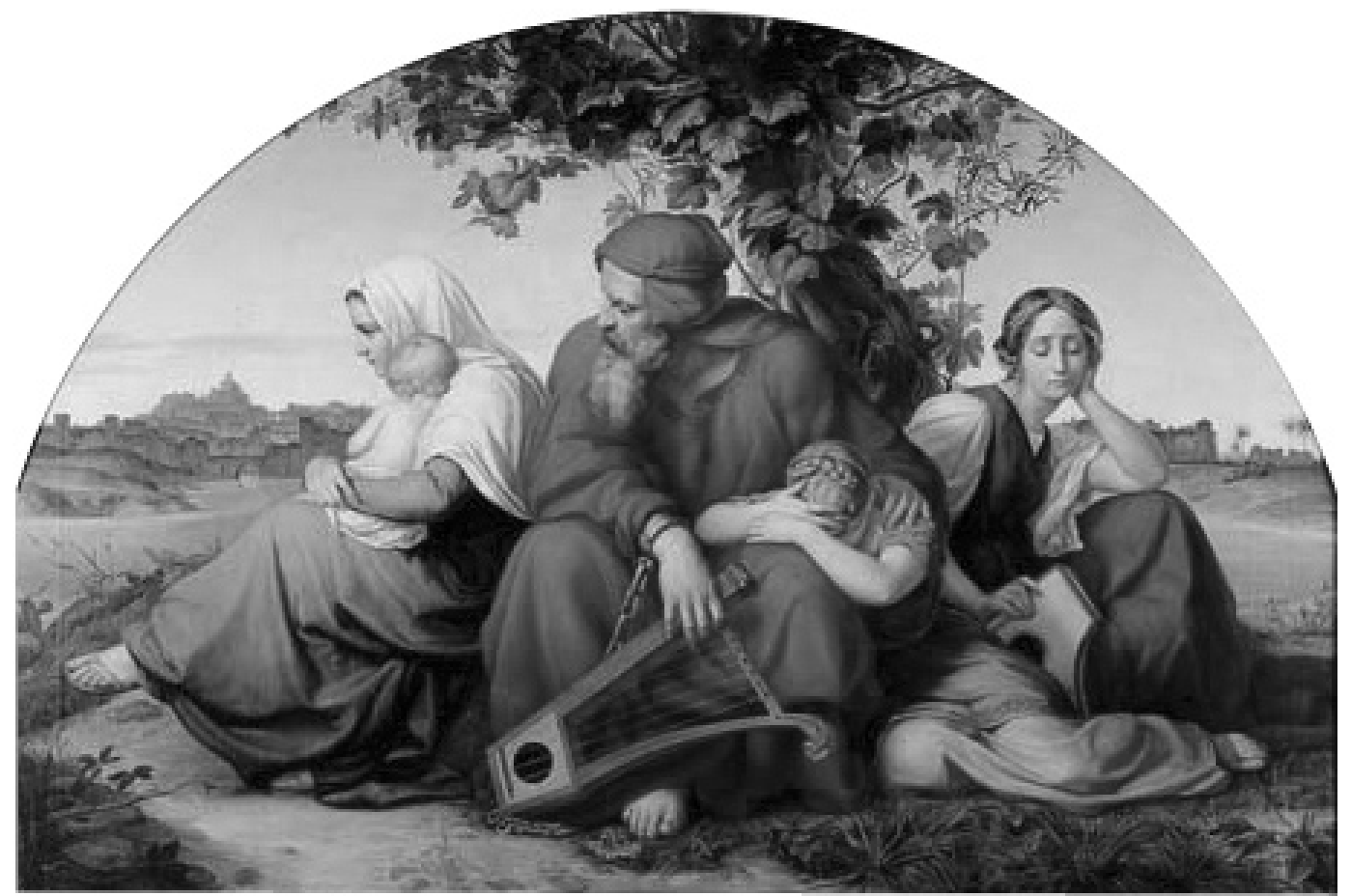

Eduard von Bendemann (1811-1889), Die trauernden Juden in Babylon (1832 vollendet - Walraff-Richartz-Museum \& Fondation Corboud in Köln). In den Zwickeln der Rahmung wurde der Beginn des 137. Psalms angebracht: „An den Wassern zu Babijlon saßen wir und weineten wenn wir an Zion gedachten”.

kündigte Joseph Mendelssohn dem Neffen an, dass er ihm das Bildnis des Großvaters zusammen mit der Biographie überbringen lasse, die er für den ersten Band geschrieben habe. ${ }^{55}$ Der Onkel beendet den Abschnitt mit der Notiz: „Von der Biographie kann ich Dir nur sagen, sie ist wahr, die Kluft welche in den Lebensverhältnißen des Großvaters und des Enkels [also Felix Mendelssohns] liegt wird Dich in Verwunderung setzen. Wenn die moralische Welt immer solche Riesenschritte machte; so wäre es unbegreiflich daß sie in 5000 Jahren nicht weiter vorgeschritten ist. Rückschritte scheinen also zur Weltordnung zu gehören und als solche muß man sie ruhig mitansehen." Joseph Mendelssohn war dem Judentum treu geblieben, nicht - so Julius H. Schoeps - weil er von seiner Wahrheit überzeugt gewesen wäre, sondern weil er die Abkehr davon als Verrat am Vater, an Moses Mendelssohn, empfunden hätte. ${ }^{56}$ So denkt er denn über den Gang der Weltgeschichte nicht anders als Abraham, der jüngere, 1835 verstorbene Bruder. Der Satz, mit dem er dem 34jährigen Neffen den gewaltigen Abstand zwischen seinem guten, glücklichen Leben und dem Leben des Großvaters zu erklären sucht, zeigt es eindrücklich. Joseph Mendelssohn erklärt die Distanz zur Auswirkung des großen, rapid vollzogenen Fortschritts, den die „moralische Welt" seit den Tagen Moses Mendelssohns getan habe. Dieser Fortschritt war es also, der den Großvater den Kindern und Enkeln

55 Dazu: Julius H. Schoeps, Das Erbe der Mendelssohns, Frankfurt a. M. 2009, S. 81. - Die Ausgabe erschien unter dem Titel Gesammelte Schriften, hrsg. von Georg Benjamin Mendelssohn in sieben Bänden, Leipzig 1843 bis 1845. 56 Schoeps, S. 81. 
entrückt und entfremdet hat. Die Nachkommen standen innerlich deshalb wohl nur insoweit hinter der Ausgabe, als sie den Beginn dieses Fortschritts dokumentierte. Im Übrigen und im Wesentlichen aber war sie ein Akt der Pietät.

Im September 1845 teilte Friedrich Schneider, der Komponist, Mendelssohn mit, dass das Geburtshaus des Großvaters in Dessau bekannt und erhalten sei. Mendelssohn lässt ihn wissen, dass er „, auf irgend eine Weise dort das Andenken an den Großvater auch äußerlich" befestigt zu sehen wünsche: „am liebsten durch eine einfache Gedenktafel über der Thür, mit einer Inschrift oder dgl. ${ }^{\text {} 57}$

\section{Vorläufiges Fazit}

Als was hat sich Mendelssohn betrachtet? Gewiss nicht als Juden. Für den Gedanken, dass ihn die jüdische Herkunft insgeheim geprägt hätte, findet sich nirgends in der Korrespondenz ein Beleg. Das Wort Synagoge kommt in Mendelssohns Briefen - soviel ich sah - nicht vor. ${ }^{58}$ Mendelssohn hat sich ausdrücklich nur selten über Jüdisches geäußert, so selten, dass es schwer fällt, die disparaten Aussagen darüber als Momente eines konsistenten Themas anzusehen. Wenn es etwas gibt, was die Sätze einigt, dann ist es seine Neigung, Distanz zu Jüdischem zu wahren und wohl auch zu bekunden. Diese Neigung betraf nicht den Umgang mit Juden. ${ }^{59}$ Mit ihnen ging er so unbefangen um wie mit römischen und rheinischen Katholiken. Es ist im Übrigen wohl kein Zufall, dass sich die problematischen Sprüche über Juden und Jüdisches nur in Briefen an die Eltern und Geschwister finden, also nur für die Familie bestimmt waren, und fast alle aus der Zeit vor 1836, also vor dem Tod des Vaters im November 1835 niedergeschrieben worden sind. Dies legt die Vermutung nahe, dass Mendelsohn den Eltern und Geschwistern zu erkennen geben wollte, dass er den Übergang vom Juden- zum Christentum bejaht und dieses, wo es angezeigt ist, praktiziert. Wenn dem so wäre, würde es bedeuten: Mendelssohn bekundete mit seinen judenkritischen Äußerungen gegenüber den Eltern und Geschwistern, dass er die Erziehung zum Christen, die die Eltern ihm, dem Unmündigen, einst hatten angedeihen lassen, vollzogen hat, bejaht und lebt, dass er denkt und redet als ein Christ, auch was die Juden angeht. ${ }^{60}$

Was nun aber war Mendelssohn, wenn er kein Jude war und sein wollte? Gewiss war er ein religiöser Mensch: ein Christ protestantischer Konfession bildungsbürgerlicher

\footnotetext{
57 FMB an Friedrich Schneider am 30. September 1845, siehe Ralf Wehner, „Friedrich Schneider und Felix Mendelssohn Bartholdy im Spiegel ihrer Korrespondenz", in: Zwischen Wörlitz und Mosigkau (= Schriftenreihe zur Geschichte der Stadt und Umgebung), Dessau 2004, S. 75 (Dokument 22).

${ }^{58}$ Einmal habe ich das Wort in einem Brief Lea Mendelssohn Bartholdys an FMB gelesen. Sie verwandte es, als sie das Bonmot eines Juden, „des berühmten Steinthal“, wiedergab. Siehe den Brief vom 30. Januar 1839, Crumb, GB-Ob, M.D.M. d. 35, Nr. 4 .

59 Ausnahmsweise fand er einmal auch an Juden Gefallen, die ihr Judentum frei und offen zur Geltung brachten. Als Gusikow, ein Jude, der die Holz- und Strohfidel virtuos zu spielen verstand, mit seinen Begleitern in Leipzig war und konzertierte, berichtete Mendelssohn über ihn und seinen Anhang begeistert den Seinen: „Sie sind alle die ächtesten, herrlichsten Polnischen Juden die man sehn kann". Seit Langem habe er sich in einem Konzert nicht mehr so unterhalten wie in dem von Gusikow, „weil er ein wahres Phänomen ist" . - FMB an Lea Mendelssohn Bartholdy am 29. Januar 1836, in: Mendelssohn, Sämtliche Briefe, Bd. 4, Nr. 1284.

60 Dass Gedanken dieser Art der Familie nicht fremd waren, kann man einem Brief Rebecka Dirichlets entnehmen. Sie moquierte sich 1836 über das überbetont christliche Getue einer vormals jüdischen Familie: „Wie erschrecklich christlich, d. h. antijüdisch sein wollend, und wie furchtbar bürgerlich und häuslich die Hitzigs sind; wie weltlich eitel, geldliebend und alttestamentarisch hingegen alles was Ebers angeht, kannst Du denken." Rebecka Dirichlet und Lea Mendelssohn Bartholdy an FMB am 12. April 1836, dazu Crumb, GB-Ob, M.D.M. d. 31, Nr. 77.
} 
Observanz. ${ }^{61}$ Wahrscheinlich hat er wie sein Vater die Konfessionen zu den historisch bedingten Äußerlichkeiten religiösen Lebens gezählt. Und gewiss war er davon überzeugt, dass Kunst, zumal eine ernsthafte bedeutsame Komposition, religiöses Leben stiften kann, dass - wie er gelegentlich schrieb - überall dort, wo eine solche erklingt, Kirche sei. ${ }^{62}$ Das erklärt die Toleranz, mit der er Andersgläubigen begegnete. Sie hat es ihm erlaubt, sich in Rom in die katholische Liturgie einzuleben, in Düsseldorf die Leitung der katholischen Kirchenmusik zu übernehmen und sie nach römischem Vorbild zu erneuern, für die hübschen Stimmen einiger römischer Nonnen lateinische Motetten, für eine Kirche in Lüttich ein umfangreiches Lauda Sion und vermutlich für den Tempel der Hamburger Juden eine Psalmkantate zu komponieren.

Mendelssohn vertraute wie sein Vater auf die modernen, national geprägten Kulturen und Kunsttraditionen. Berlin hat Mendelssohn gelegentlich seine Vaterstadt genannt, dies freilich vor allem, wenn nicht allein weil dort die Eltern und Geschwister wohnten. Nicht mit einem Wort lässt sich die Frage nach der Nation beantworten, die er als die seine betrachtete. Mendelssohn hat bekanntlich die große, zweijährige Reise durch halb Europa auch unternommen, weil er das Land in Erfahrung bringen wollte, wo er und seine Kunst danach am besten aufgenommen würden. Seine Wahl fiel schon während der Reise auf Deutschland, zunächst weil Deutschland das Land Bachs und Beethovens sowie das Goethes und Schillers war, zum andern weil er darauf vertraute, dass die Neigung und Fähigkeit der Deutschen, sich auf die große Musik der Epoche und am Ende auch auf die seine einzulassen, entschieden größer sei als die der Nachbarn. Mendelssohn war mit der Musik von Bach bis Beethoven aufgewachsen. Er hatte auf der Reise erlebt, dass selbst Musikliebhaber die Komponisten der von ihm schon so genannten klassischen Musik nur dem Namen nach kennen, und sich vorgenommen, künftig auch darauf hinzuwirken, dass ihre Werke bekannt und auf Dauer präsent gehalten würden. Er hat den Vorsatz verwirklicht, erst in Düsseldorf und dann in Leipzig. In Leipzig konnte er vollenden, was Friedrich Rochlitz und seine Mitstreiter um 1800 eingeleitet und vorbereitet hatten: die Institutionalisierung des ersten Kanons klassischer Tonkunstwerke, den es je gegeben hat. ${ }^{63}$ Ende 1836, nachdem er einen auf Dauer angelegten Vertrag mit der Direktion des Gewandhauses abgeschlossen hatte, entschied er sich endgültig für Deutschland. Mendelssohn war demnach weniger ein geborener Deutscher als ein Deutscher aus Überzeugung. Seine Entscheidung für Deutschland war ein Votum für die Musik, die er für das Non plus ultra der Epoche hielt, und zugleich ein Votum für die Musikalität der Deutschen.

Kurz, ich glaube sagen zu dürfen: Mendelssohn hat sich als Christen, als liberal gesonnenen, toleranten Protestanten betrachtet, als einen deutschen Künstler, als einen Musiker, der mit der klassischen deutschen Musik existentiell verbunden ist und es für

\footnotetext{
61 Siehe dazu: Reinhart Kosellek, „Einleitung“ in: Bildungsbürgertum im 19. Jahrhundert. Teil II Bildungsgüter und Bildungswissen, hrsg. von Reinhart Koselleck, Stuttgart 1990, S. 24 ff.

62 So FMB an Ernst Friedrich Baur am 12. Januar 1835, in: Mendelssohn, Sämtliche Briefe, Bd. 4, Nr. 1071. Vgl. dazu Wilhelm Seidel, "Absolute Musik und Kunstreligion“, in: Musik und Religion, hrsg. von Helga de la Motte-Haber, Laaber 1995, S. 91-114.

63 Wilhelm Seidel, „Friedrich Rochlitz, Über die musikgeschichtliche Bedeutung seiner journalistischen Arbeit", in: Musik und Bürgerkultur, hrsg. von Stefan Horlitz und Marion Recknagel (= Leipzig. Musik und Stadt 1), Leipzig 2007, S. 37-41.
} 
seine Aufgabe ansah, ihr Geltung verschaffen und einen Beitrag zu ihrem Fortschritt zu leisten.

\section{Richard Wagners Polemik über „Das Judentum in der Musik“ und Mendelssohn}

Eric Werner hat - wie gesagt - 1963 zur Sprache gebracht, wie man Mendelssohn und seine Musik wahrnimmt, wenn man ihn als Juden betrachtet. Ich versuchte zu erkunden, wie er über sich selbst gedacht und sich seiner Welt präsentiert hat. Die beiden Identitäten könnten verschiedener kaum sein. Und dennoch muss man sagen: Sie gehören beide Mendelssohn an, die eine, weil sich darin sein Selbstverständnis bekundet, die andere, weil sie für seine Existenz nach dem Vernichtungswerk des sogenannten Dritten Reiches steht. Es ist unmöglich, sie zu mischen oder zur Deckung zu bringen; und es wäre unangemessen, die eine gegen die andere auszuspielen. Denn sie stehen für verschiedene Phasen seiner Existenz: die eine galt für sein Leben, die andere prägte nicht allein, aber weithin übermächtig sein Nachleben.

Wagner hat das Motiv, das das Nachleben schließlich dominieren sollte, 1850, drei Jahre also nach dem Tod Mendelssohns, mit der Schrift über Das Judentum in der Musik in die Mendelssohnrezeption eingeführt. Das fordert eine Erweiterung des Skopus. Denn man kann nicht über Mendelssohn und das Judentum räsonieren, ohne auf Wagners Schrift ${ }^{64}$ einzugehen.

Die Abhandlung wird heute im Allgemeinen als Dokument des Hasses gelesen, mit dem Wagner den Juden begegnete. In Leipzig las man sie 1850 anders, als Zeugnis einer „einseitigen, geringschätzenden, höhnenden“, missbräuchlichen Musikkritik, einer Kritik, die hochverdiente Männer aburteilt und Werken das Daseinsrecht abspricht, die ,j,edem mit klaren Augen sehenden Künstler vom Fach so wie Laien, lieb und theuer" seien. ${ }^{65}$ Die Leipziger Musiker fühlten sich und ihre Stadt von dem Aufsatz verhöhnt und reagierten mit Empörung darauf. ${ }^{66}$ Sie hatten wohl recht: Wagner hatte, als er ihn niederschrieb, wenn nicht allein, so doch hauptsächlich das Leipziger Musikleben im Blick. ${ }^{67}$

Wagner kannte die Stadt und hatte wenig Grund, mit Wohlgefallen darauf zurückzublicken. ${ }^{68}$ Man muss es sich in Erinnerung rufen: Wagner war in Leipzig geboren und in der Thomaskirche getauft worden. Er war Schüler der Nicolai- und der Thomasschule gewesen. Er hatte in Leipzig die Musik, namentlich die Beethovens, für sich entdeckt. In der Wohnung, die einst die Bachs war, hatte ihn der damalige Thomaskantor Theodor Weinlich die Kunst des Kontrapunktierens gelehrt. In Leipzig waren seine ersten Kompositionen, Ouvertüren und eine Sinfonie, entstanden und aufgeführt worden. Doch, als er erste Opern vorzuweisen hatte und es darum ging, sie aufzuführen, ließ man

\footnotetext{
${ }^{64}$ Richard Wagner, „Das Judentum in der Musik“, in: ders., Gesammelte Schriften, hrsg. von Julius Kapp, Bd. 13, Leipzig 1914, S. 7-28. Die Schrift erschien zunächst unter dem Pseudonym Freigedank in der in Leipzig erscheinenden NZfM im September 1850.

65 Walter Lange, Richard Wagner und seine Vaterstadt, Leipzig 1933, S. 158.

66 Siehe dazu: Markus Erb-Szymanski, „Wider die ,Leipziger Clique'. Richard Wagners Abhandlung Über das Judentum in der Musik als antiklassische Streitschrift", in: Musik und Bürgerkultur (= Leipzig. Musik und Stadt. Studien und Dokumente 2), Leipzig 2007, S. 387-433.

67 Wagner setzte sich in dem Text auch mit Meyerbeer auseinander, vermutlich um die auf Leipzig zielende Polemik zu verallgemeinern.

68 Darüber: Lange, Richard Wagner.
} 
ihn im Stich und nahm weder die Feen noch das Liebesverbot an. Selbst nachdem er in Dresden mit dem Rienzi, dem Fliegenden Holländer und dem Tannhäuser erfolgreich hervorgetreten war, weigerten sich die Leipziger, ihm, dem Sohn der Stadt, ihr Opernhaus zu öffnen. Wagner wusste sehr wohl, woran dies letztlich lag: Es war die Fixierung der Leipziger, der führenden Musiker wie des Publikums, auf die Musik der klassischen Komponisten und ihrer Nachfolger, die der Aufnahme seiner Werke im Wege stand. Solange Mendelssohn lebte, hielt er still. Drei Jahre nach dessen Tod sah er wohl die Zeit für gekommen, die von ihm so genannte „Leipziger Clique" ${ }^{\prime 69}$ anzugehen und den Streit über den musikalischen Klassizismus und seine Kunst zu eröffnen.

Die Abhandlung über Das Judentum in der Musik war, obwohl ihr Titel scheinbar anderes ankündet, eine Polemik gegen den musikalischen Klassizismus. ${ }^{70}$ Wagner ging darin hart mit dessen Vertretern ins Gericht. Er warf ihnen vor, an überlebten Techniken festzuhalten, abgegriffene harmonische Gänge zu wiederholen und sich abgetaner Formen, Figuren und Ausdrucksmodelle zu bedienen. Damit ließen sich - gab er zu - regelgemäße, formschöne und gefällige Tonstücke verfertigen, aber keine Musik schaffen, die zu den Menschen spricht und sie ergreift. Denn nichts, was im Herkömmlichen verharre, habe Tiefe, entspringe dem Quell, der allein originale und wahrhaft sprechende und dauerhafte Musik speise. Kurz: Wagner sprach den Produktionen der klassizistisch gesonnenen Leipziger Komponisten Kunstcharakter, Wirkung und Dauerhaftigkeit ab. ${ }^{71}$

Vermutlich um diesem Urteil Schlagkraft zu verschaffen, bediente sich Wagner eines fatalen Vergleichs. Er brachte den Charakter klassizistischer Musik in Zusammenhang mit dem, was er für jüdisches Wesen hielt, und behauptete, ihre Bewegungen glichen den Bewegungen von Juden, seien ebenso leer, geschwätzig und unangenehm wie deren Sprache und Lebensäußerungen. ${ }^{72}$ Daraus schloss Wagner, dass klassizistische Musik, unabhängig davon, ob sie ein Jude oder ein Nichtjude verfertigt hat, ${ }^{73}$ "Judentum in der Musik" Geltung verschafft. Diese polemische Wende erlaubte es ihm, Mendelssohns Musik zu leerem Getön und zum Inbegriff des Jüdischen in der Tonkunst zu erklären. Dabei kam es ihm ersichtlich zupass, dass Mendelssohn der Spross einer jüdischen Familie war. Denn so konnte er ihn den Lesern als geborenes Haupt des jüdisch denkenden und handelnden Leipziger Klüngels insinuieren und am Ende der Schrift in pathetischer Manier seiner Musik den Untergang prophezeien. ${ }^{74}$ Dass er mit dem Ende der klassizistischen Tonkunst die Hoffnung auf den Sieg seiner Dramen verband, ist gewiss, auch wenn er darauf verzichtet hat, ihr eigens Ausdruck zu geben.

\footnotetext{
${ }^{69}$ Markus Erb-Szymanski, „Wider die ,Leipziger Clique'“.

70 Das Wort fällt nicht und wird in der Musikgeschichtsschreibung selten oder nur mit Vorbehalt verwandt. Ich bezeichne damit die musikalische Kunstrichtung, deren Vertreter die OEuvres der klassischen Komponisten als einen, wenn nicht als den absoluten Höhepunkt der Musikgeschichte ansahen und ihre eigene Produktion daran orientierten. Dazu: Friedhelm Krummacher, Art. „Klassizismus“, in: MGG2, Sachteil 5, Kassel u. a. 1996, Sp. 241-247.

71 Wagner, S. 17 und $26 \mathrm{ff}$.

72 Um diese Unabhängigkeit unmissverständlich festzustellen, sprach Wagner (S. 29) einen wirklichen Juden - Ludwig Börne - vom Judentum frei, weil er in ihm einen Mann erkannte, der wie er selbst aus den wahren und tiefen Quellen menschlichen Wesens schöpfe.

73 Dass man einen Juden an seinen Bewegungen erkennen könne, vermerkte gelegentlich auch Rebecka Dirichlet. Sie schrieb, nachdem sie Carl Seydelmann in der Rolle Nathans, des Weisen, gesehen hatte, dem Bruder nach Düsseldorf: „Und wie schön, wie nobel sieht er aus, man muß in jeder Bewegung den Juden erkennen, ohne daß er natürlich, ge"mauschelt hätte, er erinnerte mich an Bendemanns trauernden Juden." Rebecka Dirichlet an FMB am 18. April 1835, dazu Crumb, GB-Ob, M.D.M. d. 30, Nr. 33.

${ }^{74}$ Wagner, S. 29.
} 
Wagners Schrift ist es zuzuschreiben, dass man nach 1850 Mendelssohn nach Belieben zum Juden erklären und in die Welt zurückversetzen konnte, die schon die Eltern verlassen hatten und der er selbst nie angehört hatte. Zugleich konnte man seine Musik mit den diffamierenden Attributen belegen, mit denen Wagner das Judentum in der $\mathrm{Mu}-$ sik versehen hatte. Schlimmer freilich als dies war, dass die Schrift als Angriff auf die Juden selbst gelesen werden konnte. Wagner hat viel, wohl das meiste dazu beigetragen. Er hat die Juden über viele Seiten hin so rücksichtslos diffamiert, dass viele Leser darüber das Ziel der Abhandlung, wenn sie es denn überhaupt je wahrgenommen hatten, aus dem Blick verloren und den Text als Ausdruck reiner Judenfeindschaft und Judenhetze gelesen haben. ${ }^{75}$ Und so mutierte Wagners Plädoyer für eine neue musikalische Richtung in eine Schmähschrift gegen die Juden, auf die sich Judenfeinde bis hin zu den Nationalsozialisten stützen und berufen konnten.

Damit ist das Thema freilich nicht erschöpft. Denn Wagner hatte mit dem Titel seiner Schrift - so paradox es zu sein scheint - eine Formel geprägt, die sich schließlich auch gegen ihn selbst kehren ließ. Überlebende des Holocausts haben den Titel „Das Judentum in der Musik", unter den Wagner 1850 seinen Einspruch gegen den Klassizismus in der Musik gestellt hatte, umgedeutet und als Zeichen und Bestätigung dafür verstanden, dass es originäre jüdische Kunstmusik gegeben hat und gibt. Alexander Ringer, der ein ähnliches Schicksal zu erleiden hatte wie Eric Werner, hat mir dies mehr als einmal mit großem Ernst und großer Eindringlichkeit gesagt. Es befriedigte ihn ersichtlich, dass er den Titel der Schrift, mit der Wagner das Judentum in der Musik herabgesetzt hatte, umdenken und zum Ansatz einer Kunstgeschichte der jüdischem Musik erklären konnte. Was Ringer dazu befähigte, lässt die Aufsatzsammlung, die er 1990 publiziert hat, vielerorts erkennen. Ringer kehrte das Werturteil um, auf das Wagner seine Polemik über jüdische Musik gegründet hatte: Er setzte nicht wie dieser auf Emanationen unergründlicher seelischer Tiefen, sondern auf Produkte musikalischer Rationalität, in Sonderheit auf solche „of Jewish cerebralism ${ }^{\prime 76}$. Dass Mendelssohn in der Geschichte einer so gedachten jüdischen Musik ein prominenter Platz zukam und zukommt, versteht sich von selbst. Eric Werners Buch, das eingangs vorgestellt wurde, steht dafür.

\footnotetext{
${ }^{75}$ In den 1869 an Marie Muchanoff, geb. Gräfin Nesselrode, gerichteten „Aufklärungen über das Judentum in der Musik“ äußerte sich Wagner verärgert über die Unfähigkeit seiner Kritiker, weil sie das Gesagte verdrehten und verfälschten und ihn mit nichts anderem zu belangen wüssten als mit der "für unsere aufgeklärten Zeiten so schmachvollen, mittelalterlichen Judenhaßtendenz", Wagner, S. 32.

${ }_{76}$ Alexander L. Ringer, Arnold Schoenberg. The Composer as Jew, Oxford 1990, S. VIII.
} 